\title{
Squamous Cell Carcinoma: A Stranger in The Breast
}

\author{
Vani D, Sheelashree A N, Apoorva N* and Bharthi M \\ Mysore Medical College and Research Institute
}

\section{ABSTRACT}

In routine clinical practice, invasive ductal carcinoma of breast is commonly encountered. However strangers do knock the door sometimes and squamous cell carcinoma of breast is one such entity. Although clinical and radiographic features are not specific to this tumour it follows an atypical presentation in terms of tumour size, lymphnode and systemic spread. Usually Squamous cell carcinomasof the breast are triple negative tumours with aggressive behavior and are resistant to standard chemotherapeutic regimens.

Keywords: Squamous Cell Carcinoma, Breast, Aggressive, Triple Negative

\section{Introduction}

Invasive breast carcinoma is the most common carcinoma in women, accounting for $23 \%$ of all cancers in women worldwide. ${ }^{[3]}$ Invasive breast carcinoma - No special type is the routinely encountered type of breast carcinoma comprising between 40 and $75 \%$ of cases in published series, however it is not uncommon to find other rare variants of carcinoma breast. Metaplastic carcinomas account for 0.2 to $5 \%$ of all invasive breast cancers of which the squamous cell carcinoma is an extremely rare variant and constitutes $<0.1 \%$ of all primary invasive breast carcinomas. ${ }^{[3]}$ The mean age at diagnosis of Squamous cell carcinoma was 64 years according to California Cancer Registry data pertaining to breast carcinomas diagnosed between 1988 and 2005. ${ }^{[1][5]}$ The clinical and radiographic features are not specific to this tumour. We herein, report a case of rare breast malignancy and review the literature.

\section{Case Report}

A 51 year old female patient presented with right breast lump since one and half months, with gradual increase in size and associated pain of one week duration.

On examination a hard lump measuring $6 \times 4 \mathrm{~cm}$ was noted in the outer lower quadrant of right breast with overlying skin showing nipple retraction and redness.

On ultrasound an ill - defined heterogenous lesion with specks of calcification was noted in the outer lower quadrant and an impression of evolving abscess was made, FNAC was suggested to rule out of inflammatory carcinoma of breast. Following which FNAC was done and was reported as Right Breast Duct carcinoma and true cut biopsy with Immunohistochemistry was advised.
As a definitive treatment modified radical mastectomy was done.

On gross examination a well circumscribed lesion with central cystic area containing friable material within was noted. Microscopically the tumour showed nests of neoplastic cells having squamoid differentiation with surrounding chronic inflammatory infiltrate. The axillary lymph nodes were reactive. Further immunostaining for EGFR showed diffuse membranous positivity.

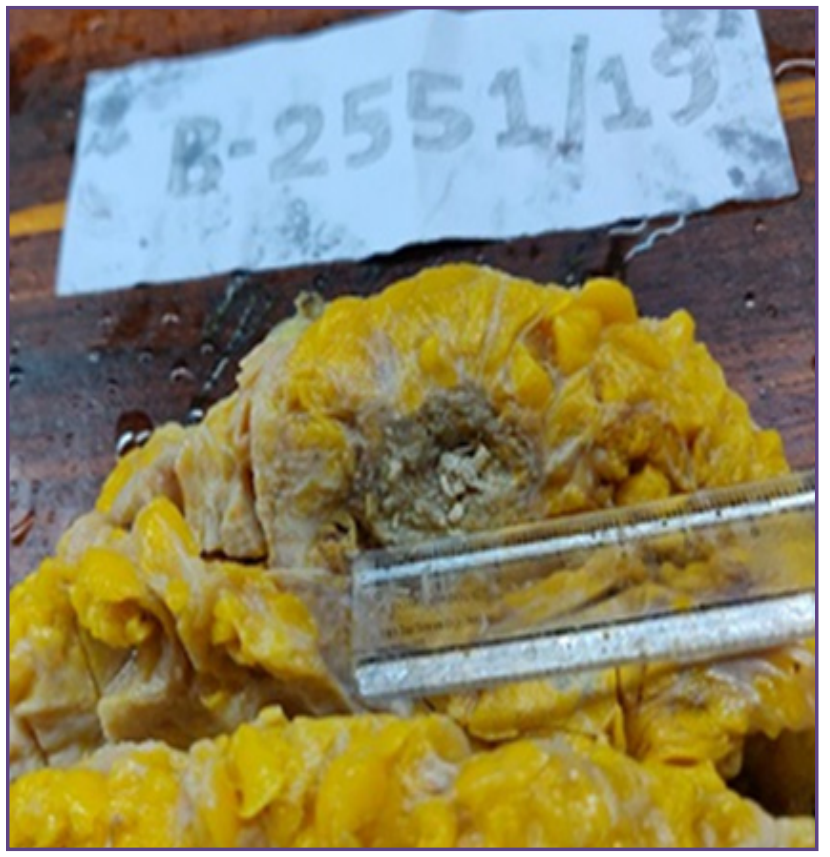

Fig. 1: Cut section of the tumour shows a central cystic area with granular friable debris. 

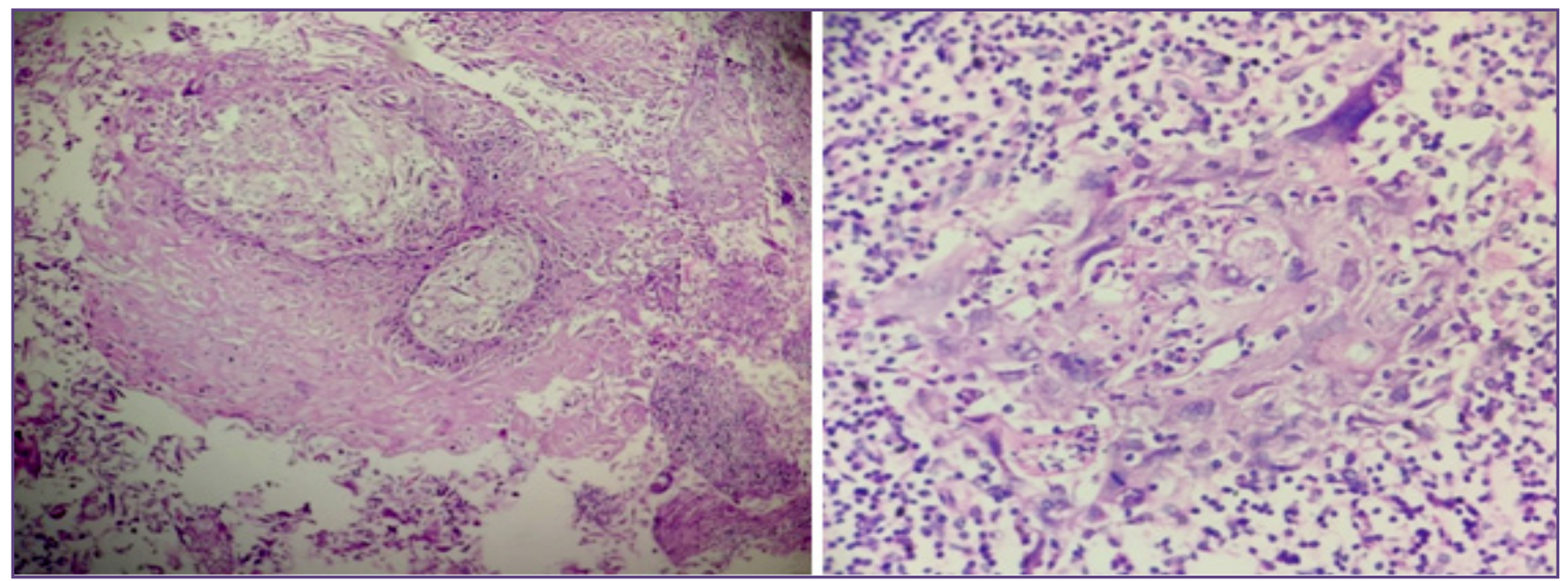

Fig. 2a and 2b: Low power view of the same tumour showing nests of neoplastic cells having squamoid differentiation.2b: Tumour cell nest surrounded by inflammatory stroma. (10x and 40x)(H\&E stain).

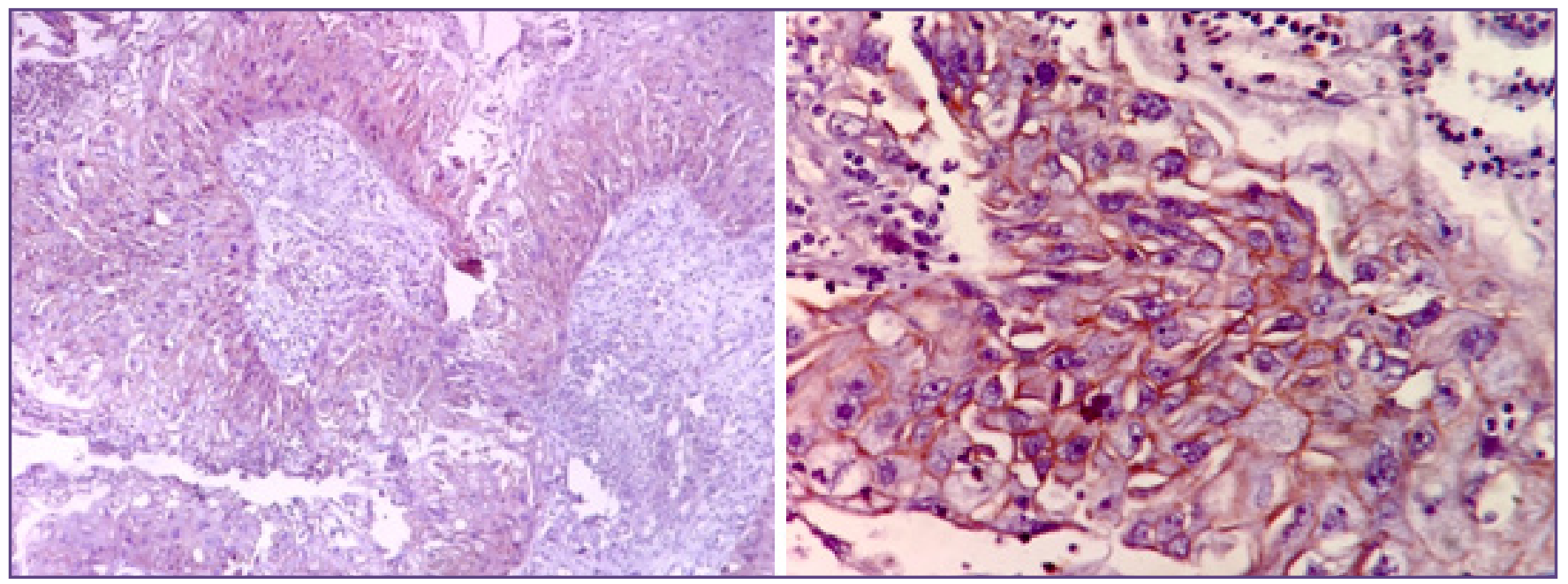

Fig. 3a and 3b : Tumour cell nests displaying EGFR positivity (10x and 40x)(IHC).

\section{Discussion}

Squamous carcinoma of the breast is a form of metaplastic carcinoma. The criteria required to diagnose Squamous carcinoma of breast are, the tumors in which $90 \%$ or more of the lesion consists of keratinizing Squamous cell carcinoma, centered in the breast parenchyma, that may involve the skin only peripherally, thus excluding any primary cutaneous neoplasm extending into the breast secondarily and metastasis of Squamous cell carcinoma from an extramammary site should be ruled out clinically.$^{[1]}$

In addition to these, tumours in which the squamous component is a portion of an otherwise typical phyllodes tumor should be excluded. ${ }^{[2]}$ It is also important not to misinterpret the syncytial areas of carcinoma with medullary features or the partial apocrine changes sometimes seen in other tumors as representing squamous change. ${ }^{[2]}$ The origin of squamous cell carcinoma of breast is still a matter of debate. The various hypothesis that have been put forward are, that pure squamous mammary carcinomas originate from benign squamous metaplasia that can occur in various conditions like the epithelium of cysts, in hyperplastic ducts, lobules, other inflammatory or necrotizing lesions such as infarcted adenomas, in inflamed cysts, fat necrosis or other forms of mastitis, in infarcted papillomas, adenomyoepitheliomas, and in healing biopsy sites. ${ }^{[1]}$ It may also directly arise from the epithelium of the mammary ducts, also immunoprofile studies have suggested dual epithelial and myoepithelial differentiation, an observation that implies possible myoepithelial origin of mammary Squamous carcinoma. ${ }^{[1]}$ 
Clinically Squamous carcinoma breast is indistinguishable from other breast malignancies and also do not show any typical mammographic appearances except for microcalcifications. ${ }^{[4]}$

The lesions characteristically present as central cystic degeneration filled with necrotic squamous and inflammatory debri. ${ }^{[1]}{ }^{[4]}$ The tumor tends to be softer and more granular when the lesion is composed largely of keratinizing epithelium. ${ }^{[1]}$

Microscopically these tumours resemble their counterparts elsewhere and it is not uncommon to find focal pseudosarcomatous and acantholytic patterns. ${ }^{[1][2]}$

These tumors are usually hormone receptor and HER2/neu negative while EGFR is frequently over-expressed. ${ }^{[3]}$

Appropriate management of Squamous cell carcinoma is controversial. Initial treatment is surgical by mastectomy with axillary clearance. ${ }^{[6][12][13]}$ Squamous carcinoma has been reported to be resistant to standard chemotherapy for Invasive ductal carcinoma, but was found to respond to cisplatinum-based chemotherapeutic regimen like those of Primary Squamous cell carcinoma at other sites . ${ }^{[4]}$ Radiotherapy has a role in management of locally advanced disease at presentation. Prognostically Squamous carcinoma was found to be equally aggressive as grade-3 poorly differentiated hormone-receptor negative adenocarcinoma ${ }^{[4][6]}$

\section{Conclusion}

In conclusion, although pure squamous cell carcinoma of breast are infrequent it is of utmost importance to recognize these strangers, as they are very aggressive, treatmentrefractory tumours with poor prognosis.

\section{Abbreviations}

FNAC: Fine needle aspiration cytology

H\&E- Hematoxylin and eosin

IHC: Immunohistochemistry

EGFR:Epidermal growth factor receptor

HER2/neu: Human epidermal growth factor receptor 2

\section{References}

1. Edi B. Squamous carcinoma. In : Ryan shaw. Rosen's breast pathology. 4th ed. Philadelphia: Lippincott williams \& wilkins, a wolters kluwer; 2014:599-610.

2. Laura C. Collins. In:Asmita Shirali. Rosai and Ackerman's Surgical Pathology. 11th Ed. Philadelphia: Elsevier Inc., 2018: $1435-1512$

3. Lakhani S, Ellis I, Schnitt S, et al. WHO Classification of Tumours of the Breast. 4th ed. Lyon: IARC Press; 2012:4852.

4. Gupta N, Vashisht R, Nimbran V, et al. Primary Squamous Carcinoma Of The Breast: Case report and management decisions. J Can Res 2012;8:323-325

5. Grabowski J, Saltzstein SL, Sadler G, et al. Squamous cell carcinoma of the breast: a review of 177 cases. Am Surg 2009;75:914-917

6. Beharanwala KA, Nasiri N, Abdullaha N, Trott PA, Gui GP. Squamous cell carcinoma of the breast: Clinicopathologic implications and outcome. Eur J Surg Oncol 2003;29:386-9

7. Kokufu II, Yamamoto M, Fukuda K, et al. Squamous cell carcinoma of the breast: three case reports. Breast Cancer 1999;6:63-68.

8. Kwak JY, Park HL, Kim JY, et al. Imaging findings in a case of epidermal inclusion cyst arising within the breast parenchyma. J Clin Ultrasound 2004;32:141-143.

9. Soderstrom KO, Toikkanen S. Extensive squamous metaplasia simulating squamous cell carcinoma in benign breast papillomatosis. Hum Pathol 1983;14:1081-1082.

10. Toikkanen S. Primary squamous cell carcinoma of the breast. Cancer 1981;48:1629-1632.

11. Eusebi V, Lamovec J, Cattani MG, et al. Acantholytic variant of squamous- cell carcinoma of the breast. Am J Surg Pathol 1986;10:855-861.

12. Hennessy BT, Krishnamurthy S, Giordano S, et al. Squamous cell carcinoma of the breast. J Clin Oncol 2005;23:78277835 .

13. Cardoso F, Leal C, Meira A, et al. Squamous cell carcinoma of the breast. Breast 2000;9:315-319.

*Corresponding author:

Dr. Apoorva N, Room no. 60, PGs and Interns womens hostel, Opp. Nanjaraj bahadur choultry, Vinobha road,

Near Metropole Circle, Mysore- 570005 INDIA

Phone: +91 8904296255

Email: apoorva.n.reddy@gmail.com

Financial or other Competing Interests: None. 